\title{
A Particulate Isotopic Standard of Plutonium in an Aluminosilicate Matrix
}

\author{
J. J. Stoffel(s), W. C. Cannon, and D. M. Robertson \\ Pacific Northwest Laboratory, Richland, Washington, USA
}

\begin{abstract}
Plutonium isotopic microstandard particles have been produced for mass spectrometer calibration. The particles may also be useful as an elemental standard for calibration of electron and ion microprobe instruments. The standard consists of spherical, micrometersize aluminosilicate particles loaded with plutonium of known isotopic distribution. The morphology, elemental composition, and plutonium isutopic composition of the particles have been characterized. (J Am Soc Mass Spectrom 1991, 2, 81-84)
\end{abstract}

$\mathrm{E}$ nvironmental contamination around nuclear facilities is receiving increased attention. Soil is one environmental medium that is commonly monitored for contamination by uranium, its fission products, and transuranic elements. Assessing the environmental impact of a nuclear facility by soil sampling and analysis may be complicated by the presence of nuclear materials from other sources. For example, plutonium may be present in soil not only from facility operations but also as fallout from atmospheric testing of nuclear weapons, from burnup of nuclear-powered satellites, and from reactor accidents such as the one at Chernobyl.

Isotopic analysis by mass spectrometry provides the most distinctive characteristic of plutonium and other radionuclides that may be relatable to the source of contamination. The sample processing for mass spectrometric analysis usually results in measurement of an average isotopic composition for all the plutonium in the sample. When plutonium from multiple sources is present, that detailed information is obliterated by the analytical process. To associate environmental contamination with a specific facility, the isotopic composition of individual plutonium-bearing particles may have to be determined.

Some ability to separate global fallout plutonium from Nevada Test Site plutonium on the basis of acid leachability of total samples has been reported [1]. Even in that case, however, integrated values were obtained for the two separated fractions, which were presumed to contain particles with different isotopic compositions.

We measure trace levels of uranium, plutonium, and other radionuclides in environmental samples by thermal ionization mass spectrometry. For analysis of particles, the mass spectrometer is calibrated with

Address reprint requests to Jim Stoffel(s), P7-07, Pacific Northwest Laboratory, P.O. Box 999, Richland, WA 99352-0999. particulate isotopic standards to maintain the accuracy of analytical results. Several particle standards of uranium have been available for this purpose [2]. However, a similar plutonium standard has not been available.

We have now produced a particulate plutonium isotopic standard. The standard consists of spherical, micrometer-size aluminosilicate particles loaded with a minor concentration of isotopically certified plutonium. This matrix and plutonium concentration are analogous to real environmental particles. Plutonium particles that reach the environment are typically submicrometer in size and become aggregated with soil or dust particles $[3,4]$.

\section{Particle Standard Production}

The particle production process involved the generation of a plutonium-labeled fused-clay aerosol $[5,6]$ and the subsequent size separation of generated particles in a centrifugal aerosol spectrometer [7]. These operations were conducted in glove boxes equipped to prevent the release of plutonium particles to the workplace or the environment.

Production began with a colloidal suspension of a high-purity aluminosilicale clay (Inhalation Toxicology Research Institute, Lovelace Biomedical and Environmental Research Institute, Albuquerque, NM). Ion-exchange sites on the clay particles were charged with sodium. The sodium was then exchanged with plutonium ions in solution. The plutonium-charged clay was collected on a filter, and the released sodium and excess plutonium were washed off. The charged clay was resuspended. Droplets of the suspension were generated with a nebulizer and passed through a tube furnace at $1150^{\circ} \mathrm{C}[5,6]$. At this high temperature, the water of hydration was driven off and the clay was "fused," thereby immobilizing the plutonium within a glassy matrix.

To serve as an isotopic microstandard, the pluto- 
Table 1. Composition of the plutonium isotopic standard CRM $138^{a}$

\begin{tabular}{ccc}
$\begin{array}{c}\text { Plutonium } \\
\text { isotope }\end{array}$ & Atom \% & $\begin{array}{c}95 \% \mathrm{CL} \\
\text { error }\end{array}$ \\
\hline 238 & 0.010 & \pm 0.001 \\
239 & 91.820 & \pm 0.010 \\
240 & 7.925 & \pm 0.010 \\
241 & 0.212 & \pm 0.001 \\
242 & 0.0330 & \pm 0.0003 \\
\hline
\end{tabular}

"Values are corrected for radioactive decay to March 1, 1989.

nium loaded into the clay was a certified isotopic standard material, CRM 138 (U.S. Department of Encrgy, New Brunswick Laboratory, Argonne, IL). (The former National Bureau of Standards (NBS) designation is SRM 948.) The standard was supplied in the form of plutonium sulfate tetrahydrate, $\mathrm{Pu}\left(\mathrm{SO}_{4}\right)_{2}$. $4 \mathrm{H}_{2} \mathrm{O}$. The isotopic composition of this standard is given in Table 1.

The polydisperse plutonium-loaded particles were passed through a centrifugal aerosol spectrometer, where they were deposited on a long foil according to their aerodynamic equivalent diameters. The foil was separated into segments, each of which held particles close to the same size. A foil segment that was known from the operating parameters of the aerosol spectrometer to hold particles close to $2 \mu \mathrm{m}$ in diameter was selected for further processing. The particles on this segment were resuspended, and individual particles were isolated for characterization.

\section{Particle Standard Characterization}

\section{Morphology}

The shape and size of particles produced were determined by scanning clectron microscopy (SEM). The instrument used was a JEOL JSM-25S scanning electron microscope equipped with a Tracor Northern TN-2000 analyzer and particle recugnition and characterization software (JEOL U.S.A., Peabody, MA).

The particles are nearly spherical, as can be seen in Figure 1. The shape results from both the collapse of the clay crystal structure when the water of hydration is driven off at $-500{ }^{\circ} \mathrm{C}$ and softening of the material at $1150{ }^{\circ} \mathrm{C}$. An average shape factor (ratio of maximum to minimum diameter) of 1.13 was determined from measurements on 41 discrete particles.

Size measurements on the same lot of 41 particles gave a count median diameter of $1.75 \mu \mathrm{m}$. The distribution of particle sizes, shown in Figure 2, has a geometric standard deviation $\sigma_{g}=1.1$. (For a discussion of the statistics of log-normal particle size distributions, see ref. 8.) Prior to measurement of the Pu-clay particles, the size measurement system was calibrated with NBS-traceable standard polystyrene latex spheres of known diameter.

The particles were shown to be amorphous by the absence of diffraction patterns with both $x$-rays and

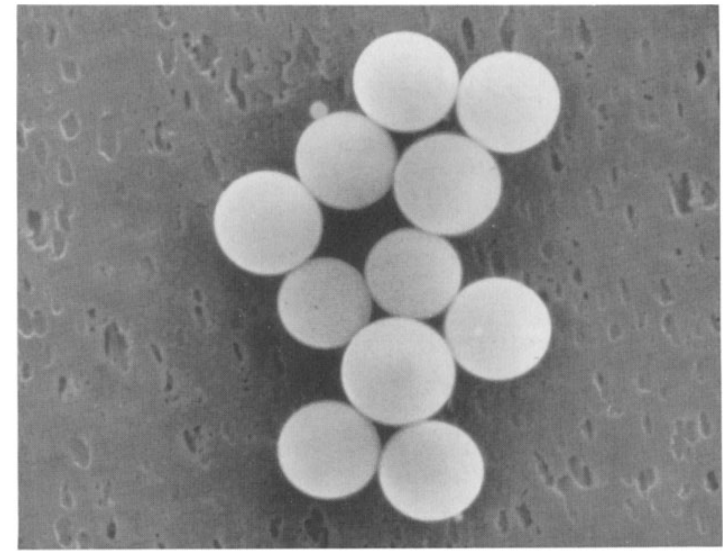

Figure 1. An aggregate of $11 \mathrm{Pu}$-clay particles. The size calibration marker is $0.94-\mu \mathrm{m}$ long.

electrons. This structure results from plastic deformation of the material at the heat-treatment temperature of $1150^{\circ} \mathrm{C}$. Although this temperature is well below the melting point of the material, the particles are referred to as "fused." The electron diffraction analysis was performed with a JEOL JEM-2000FX analytical electron microscope.

\section{Elemental Analysis}

The elemental composition of particles of the selected size was determined by the most accurate mode of wavelength-dispersive $x$-ray analysis on a JEOL JXA8600 electron microprobe. The instrument was calibrated with standards for all the elements measured. The standards were flat carbon-coated surfaces of the element or a stoichiometric compound.

Three individually mounted Pu-clay particles were analyzed three times each. The results are summarized in Table 2. The errors quoted apply only to the precision of the measurements. Larger errors in accuracy are incurred by the use of flat standards to

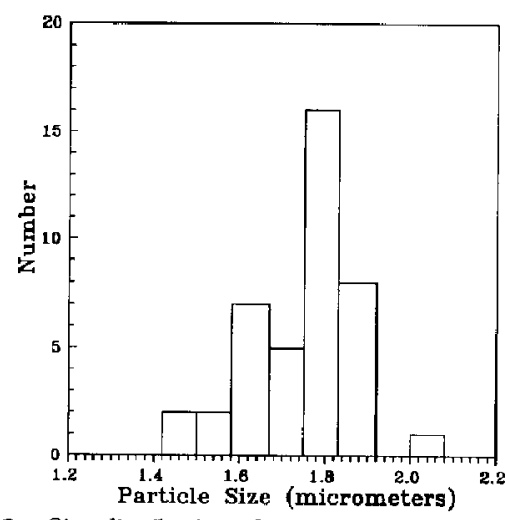

Figure 2. Size distribution of 41 Pu-clay particles. 
Table 2. Elemental analysis of three Pu-clay particles by wavelength-dispersive $x$-ray spectrometry ${ }^{a}$

\begin{tabular}{lccc}
\hline & \multicolumn{3}{c}{ Average wt\% \pm 10 error } \\
\cline { 2 - 4 } Element & Particle 1 & Particle 2 & \multicolumn{1}{c}{ Particle 3 } \\
\hline \hline $\mathrm{Na}$ & $0.17 \pm 0.02$ & $0.19 \pm 0.02$ & $0.33 \pm 0.03$ \\
$\mathrm{Mg}$ & $4.96 \pm 0.07$ & $5.05 \pm 0.07$ & $4.95 \pm 0.00$ \\
$\mathrm{Al}$ & $11.16 \pm 0.04$ & $11.14 \pm 0.04$ & $11.12 \pm 0.02$ \\
$\mathrm{Si}$ & $30.86 \pm 0.04$ & $30.77 \pm 0.08$ & $30.75 \pm 0.03$ \\
$\mathrm{Ca}$ & $0.54 \pm 0.02$ & $0.50 \pm 0.02$ & $0.59 \pm 0.02$ \\
$\mathrm{Fe}$ & $0.79 \pm 0.06$ & $0.88 \pm 0.04$ & $0.80 \pm 0.05$ \\
$\mathrm{Pu}$ & $2.30 \pm 0.05$ & $2.28 \pm 0.09$ & $2.28 \pm 0.07$ \\
$\mathrm{O}$ & Balance & Balance & Balance \\
\hline
\end{tabular}

a The errors quoted apply only to the precision of the measurements, not to the accuracy.

correct the raw data from particles. On NBS glass particles of similar composition and size, the accuracy errors are usually $<10 \%$ for elements present at $\geq$ $1 \%$.

Except for sodium, the elemental composition of the particles analyzed is homogeneous. Americium was not measurable by this method because it amounts to only $\sim 0.01 \%$, based on the decay of ${ }^{241} \mathrm{Pu}$ since 1962 (see below). The measured concentration of plutonium is $2.3 \mathrm{wt} \%$. For a particle density of $2.2 \mathrm{~g} / \mathrm{cm}^{3}$ [5], the following amounts of plutonium are contained in a single particle of median diameter:

\section{$0.14 \mathrm{pg}$ \\ $3.6 \times 10^{8}$ atoms \\ $0.09 \mathrm{dpm}$ or $40 \mathrm{fCi}$}

\section{Isotopic Analysis}

Plutonium isotopic analysis was performed on six individual particles. Each particle was mounted on a single rhenium filament carburized at $-1600^{\circ} \mathrm{C}$. A triple-sector mass spectrometer [9] equipped with a thermal ionization source was used for the analyses. The results of the six analyses show excellent agreement with the NBL-certified values for all isotopes. The data are given in Table 3.
The total number of ${ }^{240} \mathrm{Pu}$ ions collected during each analysis ranged from 79,000 to 395,000 . When we apply the duty factor of 0.156 for that isotope during the scan of the mass spectrum and use the median diameter, we calculate an overall mass spectrometer efficiency of 2-9\% for measuring the plutonium in these particles. This is in reasonable agreement with efficiency values of 3-5\% for plutonium in resin beads measured on the same instrument [10].

No americium interference with the measurement of ${ }^{241} \mathrm{Pu}$ was observed. The ${ }^{241} \mathrm{Am}$ content should be more than twice the ${ }^{241}$ Pu content, based on an effective americium separation date of July 6, 1962 [11] and assuming equal efficiency of loading into the clay matrix.

The evaporation of americium and other actinide elements as metal ions is promoted by carbon diffusion to the surface of the rhenium filament as the carburization temperature is exceeded [10]. No americium metal ions were observed with the filaments carburized at $1600^{\circ} \mathrm{C}$, because the americium evaporated rapidly as the carburization temperature was exceeded during the tune-up procedure. The presence of ${ }^{241}$ Am was confirmed, however, by mass spectrometric measurement of three separate particles loaded on rhenium filaments carburized at $\sim 1200^{\circ} \mathrm{C}$. Figure 3 shows $\mathrm{Am}^{+}$ion emission at mass 241 between 1200

Table 3. Isotopic analysis of six Pu-clay particles by thermal ionization mass spectrometry

\begin{tabular}{|c|c|c|c|c|c|c|}
\hline \multirow{2}{*}{$\begin{array}{l}\text { Particle } \\
\text { number }\end{array}$} & \multicolumn{5}{|c|}{ Atom $\% \pm 10$ Error } & \multirow{2}{*}{$\begin{array}{c}\begin{array}{c}\text { Total } \\
\text { counts }\end{array} \\
{ }^{240} \mathrm{Pu}\end{array}$} \\
\hline & ${ }^{2{ }^{288}} \mathbf{P u}$ & ${ }^{239} \mathrm{Pu}$ & ${ }^{240} \mathrm{Pu}$ & ${ }^{241} \mathrm{Pu}$ & ${ }^{242} \mathrm{Pu}$ & \\
\hline \multirow[t]{2}{*}{101} & 0.013 & 91.838 & 7.914 & 0.216 & 0.032 & 79,000 \\
\hline & \pm 0.003 & \pm 0.035 & \pm 0.034 & \pm 0.005 & \pm 0.002 & \\
\hline \multirow[t]{2}{*}{102} & 0.013 & 91.834 & 7.922 & 0.211 & 0.033 & 193,000 \\
\hline & \pm 0.002 & \pm 0.023 & \pm 0.022 & \pm 0.005 & $\neq 0.001$ & \\
\hline \multirow[t]{2}{*}{103} & 0.012 & 91.848 & 7.908 & 0.212 & 0.032 & 179,000 \\
\hline & \pm 0.002 & \pm 0.028 & \pm 0.028 & \pm 0.003 & \pm 0.002 & \\
\hline \multirow[t]{2}{*}{104} & 0.013 & 91.864 & 7.912 & 0.222 & 0.033 & 137,000 \\
\hline & \pm 0.003 & \pm 0.027 & \pm 0.026 & \pm 0.004 & \pm 0.002 & \\
\hline \multirow[t]{2}{*}{105} & 0.011 & 91.822 & 7.934 & 0.213 & 0.031 & 395.000 \\
\hline & \pm 0.001 & \pm 0.016 & \pm 0.015 & \pm 0.003 & \pm 0.001 & \\
\hline \multirow[t]{2}{*}{106} & 0.014 & 91.820 & 7.928 & 0.220 & 0.032 & 204,000 \\
\hline & \pm 0.002 & \pm 0.023 & \pm 0.023 & \pm 0.003 & \pm 0.002 & \\
\hline
\end{tabular}




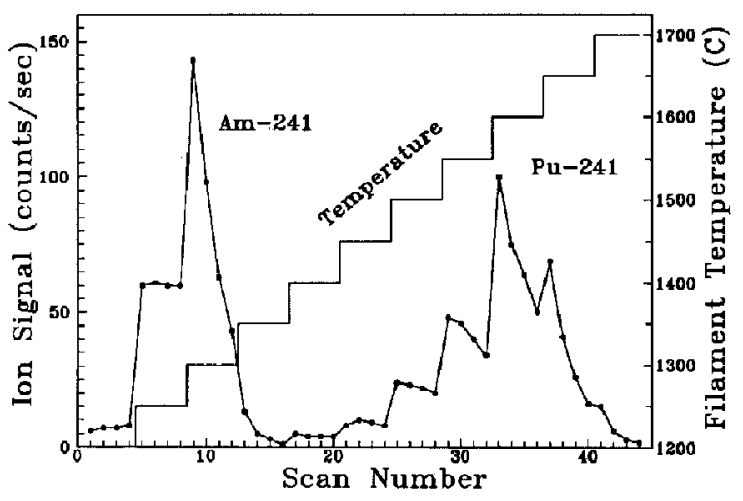

Figure 3. Ion emission at mass 241 from Pu-clay particles loaded on rhenium filaments carburized at $\sim 1200^{\circ} \mathrm{C}$. The data are averaged from the measurement of three separate particles. The time per scan is $\mathbf{4 3} \mathrm{s}$.

and $1350{ }^{\circ} \mathrm{C}$ followed by $\mathrm{Pu}^{+}$ion emission between 1400 and $1700^{\circ} \mathrm{C}$.

\section{Particle Mounting}

The plutonium isotopic microstandard particles were dispersed in a thin layer of collodion on polycarbonate microscope slides. Under optical magnification $\times 250$, the $1.75-\mu \mathrm{m}$-diameter particles appear as a diffraction ring of $\sim 1-\mathrm{mm}$ diameter. Single particles are readily distinguishable from aggregates of two or more particles.

Individual particles can be isolated from the slide mounts to serve as microstandards for calibration of isotope-ratio mass spectrometers. The particles may also be useful as an elemental standard for calibration of analytical electron and ion microprobe instruments.

\section{Acknowledgments}

The successful completion of this work was made possible only by the expert assistance of many other Pacific Northwest Laboratory staff members. T. C. Maiti put the plutonium isotopic standard into solution. G. J. Powers loaded the plutonium into the clay matrix. E. F. Blanton provided technical assistance in particle generation. $R$. R. Adee performed the particle size and shape measurements on the scanning electron microscope. $R$. M. Graves mounted individual particles for $\mathbf{x}$-ray, electron microprobe, and mass spectrometer analyses. $\mathrm{H}$. Tenny performed the $x$-ray and electron diffraction measurements as well as the elemental analyses on the electron microprobe. L. A. Bond performed the isotopic analyses on the PNL triple-sector mass spectrometer. K. R. Price provided helpful comments on the manuscript.

D. S. Simons, National Institute of Standards and Technology, provided the plutonium isotopic standard as well as helpful discussions. H. L. Rook of the NIST was instrumental in obtaining support for this work. E. P. Hardy and P. W. Krey, Environmental Measurements Laboratory, provided helpful comments on the manuscript.

We especially thank G. J. Newton, Inhalation Toxicology Research Institute, for the generous spirit of many helpful discussions.

\section{References}

1. Krey, P. W.; Bogen, D. C. J. Radioanal. Nucl. Chem. Articles $1987,115,335-355$.

2. Simons, D. S. J. Tnace Microprobe Techniques 1986, 4, 185-195.

3. McDowell, L. M.; Whicker, F. W. Health Phys. 1978, 35, 293-299.

4. Krey, P. W.; Freeswick, D. C.; Hinchcliffe, L. E. Proceedings of the American Nuclear Society: Winter Meeting 1977: pp $115-130$.

5. Raabe, O. G.; Kanapilly, G. M.; Newton, G. J. In Inhaled Particles III; Walton, W. H., Ed.; Unwin Brothers: Old Woking, England, 1971: Vol. 1, pp 3-17.

6. Newton, G. J.; Kanapilly, G.; Boecker, B. B.; Raabe, O. G. In Generation of Aerosols and Facilities for Exposure Experiments; Willeke, K., Ed.; Ann Arbor Science Publishers: Ann Arbor, 1980; pp 399-425.

7. Kotrappa, P.; Moss, O. R. Health Phys. 1971, 21, 531-535.

8. Hinds, W. C. Aerosol Technology: Properties, Behavior and Measurement of Airborne Particles; Wiley-Interscience: New York, 1982; pp 83-87.

9. Lagergren, C. R.; Stoffels, J. J. Int. J. Mass Spectrom. Ion Phys. 1970, 3, 429-438.

10. Kelley, J. M.; Robertson, D. M. Anal. Chem. 1985, 57, 124-130.

11. Kirby, H. W.; Sheehan, W. E. Nucl. Instrum. Methods 1984, $223,356-359$ 